\title{
Padrões de saúde e segurança no trabalho $e$ extrativismo: o caso de comunidades rurais da Amazônia brasileira'
}

\author{
Health and safety standards in labor and extractivism: \\ the case of rural communities in Brazilian Amazon
}

\author{
João Paulo Cândia Veiga \\ Universidade de São Paulo. Instituto de Relações Internacionais. \\ São Paulo, SP Brasil. \\ E-mail: candiaœusp.br \\ Danilo Machado Trevisani \\ Universidade de São Paulo. São Paulo, SP, Brasil. \\ E-mail: danilotreviळhotmail.com \\ Fausto Makishi \\ Universidade de São Paulo. São Paulo, SP Brasil. \\ E-mail: faustomakishiळgmail.com \\ Mariana Gomes Caixeta de Abreu \\ Universidade de São Paulo. São Paulo, SP Brasil. \\ E-mail: caixeta.mariळgmail.com \\ Maurício Saraiva Pacheco e Silva \\ Universidade de São Paulo. São Paulo, SP Brasil. \\ E-mail: mau.spsœgmail.com

\section{Murilo Alves Zacareli} \\ Universidade de São Paulo. São Paulo, SP Brasil. \\ E-mail: murilo.alveszacareliळusp.br
}

\section{Correspondência}

João Paulo Cândia Veiga

Av. Professor Luciano Gualberto, 315, sala 2.047, Cidade Universitária. São Paulo, SP, Brasil. CEP 05508-900.

\section{Resumo}

Este artigo é resultado de pesquisa de campo realizada junto aos coletores de sementes e frutos oleaginosos - Produtos Florestais Não Madeireiros (PFNMs) - em áreas rurais de Salvaterra e Bragança, no estado do Pará. O objetivo é contribuir com os estudos empíricos sobre saúde e segurança ocupacional no extrativismo, ainda incipientes no Brasil, por falta de amparo técnico-científico relacionado à atividade extrativista e por falta de regulamentação específica para a área. A pesquisa, realizada a partir da coleta de dados primários e observacionais, aponta os riscos de saúde e segurança aos quais os coletores estão expostos e os métodos de prevenção de acidentes, a fim de identificar possíveis melhorias nas condições de trabalho em um contexto onde a regulamentação de padrões trabalhistas para autônomos, informais e extrativistas na Amazônia é praticamente inexistente. A metodologia se caracteriza como estudo de caso em profundidade com coleta de dados primários com adoção de métodos mistos para sua sistematização. Os resultados demonstram que novas práticas e normas precisam ser adotadas para que os riscos à saúde e à segurança dos coletores sejam minimizados, além de garantir fiscalização, incentivo e monitoramento de práticas de segurança adequadas à atividade e específicas para cada região.

Palavras-chave: Padrões trabalhistas; Saúde e Segurança no Trabalho (SST); Extrativismo; PFNMs.

1 Pesquisa aprovada pelo Comitê de Ética em Pesquisa sob o número CAAE 41460415.2.00oo.5422 em 25/02/2015. 


\section{Abstract}

This article is the result of a field research conducted among collectors of oleaginous seeds and fruits - Non-Timber Forest Products (NTFP) - in the rural areas of Salvaterra and Bragança, in the state of Pará, Brazil. It aimed to contribute to empirical studies on health and occupational safety in extractivism, still incipient in Brazil due to the lack of technical-scientific support and the lack of specific regulation on the area. The research was conducted by the collection of primary and observational data that point out the risks to health and safety to which collectors are exposed to and the methods to prevent accidents in order to identify possible improvements to working conditions in a context in which labor regulation standards for autonomous, informal and extractive workers in the Amazon is practically inexistent. This paper's methodology is characterized as an embedded case study along with the collection of quantitative and qualitative data with the adoption of mixed methods for their systematization. The results show that new practices and norms should be adopted so the risks to health and safety of collectors are minimized, besides ensuring the inspection, incentives and monitoring of safety practices that are adequate to the activity and specific to each region. Keywords: Labor Standards; Work Health and Safety; Extractivism; NTFP.

\section{Introdução}

Os padrões de Saúde e Segurança no Trabalho (SST) aplicados à atividade extrativista é tema ainda pouco explorado pela literatura acadêmica, devido, em parte, à ausência de regulamentação pública específica e à falta de demanda por parte dos usuários. No caso da regulamentação pública internacional, a Organização Internacional do Trabalho (OIT) estabelece padrões de SST para a agricultura e atividades florestais na Convenção 184 (em vigor desde setembro de 2003). Antes mesmo da Convenção 184, os focos de regulamentação da OIT eram o uso de maquinário (motosserras, por exemplo), a saúde e segurança no transporte, e o emprego de agrotóxicos, todas consideradas atividades de risco que exigem regulação (OIT, 1968; Seixas, 1991; Bostrand, 1992; ILO, 1998). Contudo a Convenção 184 (29 artigos) prioriza as atividades florestais de grande escala e exclui a economia de subsistência como o extrativismo, precisamente aquelas em que as famílias de comunidades rurais da Amazônia fazem uso para o complemento de renda.

Há ainda Convenções da OIT para duas outras atividades extrativas. A de saúde e segurança na mineração (Convenção 176: Safety and Health in Mines Convention, em vigor desde 1998), e a de padrões trabalhistas para a pesca (Convenção 188: Work in Fishing Convention, em vigor desde 2007) (Câmara; Assunção; Lima, 2007). No primeiro caso, trata-se de uma Convenção para proteger a representação dos empregados frente às empresas mineradoras. No caso da pesca, quase todos os 54 artigos da Convenção tratam de condições de trabalho em embarcações. Alguns trabalhos discutem as condições de trabalhadores informais na indústria (Mendes; Campos, 2004). Entretanto não existe regulação da OIT para atividades de pequena escala, de subsistência e informais, em áreas rurais que envolvam o manejo de florestas.

Ainda em âmbito internacional, no caso da extração vegetal, a FAO (Organização das Nações Unidas para Agricultura e Alimentação) desenvolveu expertise técnica a respeito do extrativismo de florestas plantadas de uma perspectiva ergonômica com ênfase na identificação dos principais desafios e nas boas práticas, para que acidentes de trabalho 
pudessem ser evitados (Bostrand, 1992). Ainda nos anos 1990, a literatura internacional passou a valorizar as atividades extrativistas de pequena escala para Produtos Florestais Não Madeireiros (PFNMs) de várias perspectivas: como estratégia de preservação de áreas de reserva florestal (Viana; Mello, 1995), como alternativa de geração de renda para comunidades rurais (Allegretti, 1994; FAO, 1995), como estratégia de desenvolvimento local ou como fonte de experimentação para atividades florestais de maior produtividade (Richards, 1993; ClüsenerGodt; Sachs, 1994). Contudo, mesmo nesses casos, não houve desenvolvimento da abordagem específica para saúde e segurança direcionada a atividades de subsistência para o manejo de frutos e sementes oleaginosas como PFNMs.

De fato, os chamados produtos florestais não madeireiros (PFNMs), consagrados pela literatura internacional sob essa denominação (Peters, Gentry, Mendelsohn, 1989; Hall; Bawa, 1993; Ticktin, 2004) receberam pouca atenção da área de SST. A série do Instituto Brasileiro de Geografia e Estatística, denominada Produção da Extração Vegetal e da Silvicultura (IBGE, 2006), é a melhor fonte de informações sobre PFNMs no Brasil, mas também não traz indicações sobre SST. De todo modo, a dificuldade no desenvolvimento de agendas de pesquisa sobre SST de PFNMs tem sua razão de ser. A diversidade de sementes e as formas de coleta desses recursos naturais são muito diversas. 0 pracaxi (Pentaclethramacroloba) é coletado de canoa, com as mãos, diretamente da superfície da água em rios e igarapés. Já o murumuru (Astrocaryummurumuru) é coletado em áreas de várzea, com foice para a poda do cacho, e sua folha desenvolve espinhos que chegam a trinta centímetros de cumprimento. No caso da andiroba (Carapaguianensis), a semente é coletada em praias e igarapés, trazida pela maré. Os coletores utilizam basicamente as mãos para procurar a andiroba, que pode flutuar ou mesmo estar junto ao "lixo", folhas e galhos entremeados à vegetação que se acumula às margens de rios ou em praias. Ocorre que o lixo pode esconder objetos perfurantes, como espinhos, carcaças de peixes e animais peçonhentos, como cobras, aranhas e escorpiões (Plowden, 2004).
Ademais, soma-se ainda a falta de aparato técnico-científico, fundamentado na forma de conhecimento adquirido, já consolidado em outras atividades laborais, mas ainda inexistente para os PFNMs. É justamente essa lacuna que o presente estudo procura preencher e, assim, contribuir para a discussão a respeito de como padrões de SST podem ser interpretados e aplicados em comunidades locais extrativistas da Amazônia brasileira, a principal região de ocorrência da biodiversidade na forma de PFNMs, articulando aspectos de saúde e segurança com o conceito de sustentabilidade, entendido aqui como o uso sustentável dos recursos naturais no tempo presente e para as futuras gerações (WCED, 1987).

A temática aqui tratada é de interesse fundamental para a literatura acadêmica que discute os temas de saúde ocupacional e segurança no trabalho em várias áreas das ciências exatas e humanas. Padrões de segurança no trabalho e de saúde ocupacional são áreas de estudo consolidadas para as engenharias florestal, civil, de produção, de minas, ambiental, entre outras (Fonseca et al., 2015), para a medicina do trabalho (Câmara; Assunção; Lima, 2007), ergonomia (Bostrand, 1992; Alencar Filho, 1993; Grandjean, 1998) e também para a economia e a sociologia do trabalho que os interpretam a partir da ótica social e econômica (Câmara; Assunção; Lima, 2007). Sob a chave ambiental, essas mesmas áreas acabam articulando a discussão de saúde e segurança no trabalho ao uso sustentável dos recursos naturais (Hall; Bawa, 1993; Ticktin, 2004). Há estudos sobre a coleta de sementes em árvores no caso de atividades florestais (Seixas, 1991), na ergonomia do extrativismo e boas práticas no manejo de frutos como o açaí e andiroba (Canto, 2001; Plowden, 2004; Pinto et al., 2010; Rocha et. al., 2012; Gomes; Carvalho, 2012).

O estudo em tela identifica os riscos aos quais os coletores estão expostos e os métodos de prevenção de acidentes por eles utilizados (os chamados "saberes”) (Rêgo, 1999; Diegues et al., 200o), a fim de se propor melhorias para suas condições de trabalho no extrativismo. O outro objetivo - e não menos importante - é o de promover a discussão sobre SST no extrativismo dos PFNMs. Observa-se que a regulamentação das condições de trabalho para os 
empregados urbanos e rurais está mundialmente consolidada. Porém, quando se trata de trabalhadores autônomos, em atividades informais e de pequena escala, em locais de difícil acesso, ainda existe um grande campo a ser explorado no que se refere às garantias de saúde e segurança ocupacional e às técnicas aplicáveis à atividade de coleta de sementes oleaginosas.

A temática do extrativismo parece bastante relevante à discussão envolvendo a exploração sustentável da região amazônica. Historicamente, a Amazônia tem se constituído em um tradicional fornecedor de commodities para o mercado internacional. Desta forma, a região tem se destacado por oferecer recursos naturais - minerais, madeireiros, agropecuários e agroindustriais - a custo baixo, por meio da ação governamental no que diz respeito à indução de modelos de desenvolvimento que empregam força de trabalho abundante e de baixa qualificação (Faria, 2007; Guariguata, 2010). Sabe-se ainda que a atividade extrativista é cada vez mais relevante na economia mundial. Segundo o documento Produção da Extração Vegetal e da Silvicultura (2006), a extração vegetal representou R\$ 5 bilhões da produção primária florestal no Brasil em 2011. Neste estudo, a participação de produtos não madeireiros somou R\$̣ 935,8 milhões.

\section{Procedimentos metodológicos}

A pesquisa de campo foi realizada entre janeiro e março de 2014 e teve como objetivo analisar a atividade extrativista de comunidades rurais na coleta de PFNMs da Amazônia brasileira por meio de estudo de caso em profundidade, o chamado embedded case study (Cox, 2015), especificamente, o caso do extrativismo de frutos e sementes oleaginosas nos municípios de Salvaterra (Ilha do Marajó) e Bragança, ambos no estado do Pará. O objetivo da pesquisa foi o de verificar as condições de SST na coleta de sementes oleaginosas, e a forma como os coletores compreendem seu próprio envolvimento na atividade de coleta, ou seja, qual sua percepção acerca dos riscos nos quais estão envolvidos.

Foram aplicados questionários abertos semiestruturados para SST junto a 84 famílias em Salvaterra e outras 106 famílias em Bragança, por meio de entrevistas que duraram, em média, cerca de quinze minutos. As perguntas capturam a percepção dos coletores de frutos e sementes em relação à SST, ou seja, como eles mesmos consideram os riscos da atividade para sua saúde e segurança naquela atividade. Neste sentido, foi possível detalhar os procedimentos que envolvem a atividade da coleta, desde a captura das sementes e dos frutos (em praias, como ocorre em Salvaterra, ou em florestas e margens de rios, como ocorre em Bragança), o transporte e até o armazenamento. A equipe de pesquisadores acompanhou os coletores nas áreas destinadas à captura de frutos e sementes, ou seja, a análise sobre as práticas extrativistas em questão foi complementada pela observação in loco da rotina dos trabalhadores. A pesquisa, em seu caráter qualitativo-quantitativo, procurou combinar informações obtidas pelas entrevistas com as famílias e pela observação direta dos locais de extração. Buscou-se avaliar questões como a posição corporal durante a atividade (ergonomia), ou seja, os movimentos realizados (abaixar, agachar, levantar, flexionar os braços, carregar peso), os perigos existentes nos locais de coleta (espinhos, animais peçonhentos e objetos cortantes), os locais de coleta (praias, margens de rios, florestas com áreas secas e alagadas) e o transporte (sacas).

Estima-se que em Salvaterra existam cerca de duzentos coletores de sementes e em Bragança, outros seiscentos, segundo especialistas locais que acompanham a atividade de coleta. Segundo o IBGE (2011) as populações rurais de Salvaterra e Bragança seriam, respectivamente, de 1.900 e 9.700 famílias. A amostra (número de famílias) selecionada contempla as exigências metodológicas para populações finitas (Richardson, 1985), considerando nível de confiança de $95 \%$, precisão de $5 \%$ e taxa de crescimento da população de 1,5\% de forma que seja possível a generalização dos resultados obtidos para toda a comunidade rural dos municípios em tela.

Sobrepondo os objetivos gerais e específicos, foi possível vincular a temática de SST ao conceito de "desenvolvimento sustentável" e, ao mesmo tempo, abrir um subtema ainda pouco explorado pelas diferentes abordagens de saúde e desenvolvimento ocupacional, qual seja, a atividade extrativista da qual depende grande contingente populacional 
da Amazônia brasileira, principalmente na extração de borracha natural, e na coleta de sementes oleaginosas, frutos, folhas, e raízes. Ao final, discute-se algumas sugestões com objetivo de contribuir com uma agenda de ações e práticas para minimizar os perigos aos quais os coletores estão expostos durante sua jornada de trabalho.

\section{SST na atividade florestal}

Como os padrões de SST aplicado ao extrativismo são praticamente inexistentes, optou-se por desenvolver um breve panorama a respeito da evolução da regulação acerca de SST no Brasil. Na década de 1970, com a criação da Fundacentro, órgão ligado ao MTE - Ministério do Trabalho e Emprego, as primeiras pesquisas sobre SST foram desenvolvidas no Brasil. Com a publicação da Lei Federal N 6514/77, que alterou o Cap.V do Tít. II da CLT - Consolidação das Leis Trabalhistas e da Portaria 3214/78, que aprovou as Normas Regulamentadoras (NR) relativas à SST, houve grande avanço na promoção de melhores condições de trabalho a partir de um recorte de SST. Contudo, nesse primeiro momento, as ações, programas e políticas de SST representavam ainda tímida atitude de caráter prevencionista, iniciada pelos primeiros profissionais de saúde e segurança ocupacional por um lado, e, por outro, incentivavam comportamento punitivo e policialesco por parte dos órgãos fiscalizadores governamentais (Mazzeu; Demarco; Kalil, 2007).

Sensível evolução ocorreu nas décadas de 1980 e 1990 com as alterações das normas referentes às práticas de SST, principalmente com o PPRA - Programa de Prevenção de Riscos Ambientais (NR no 9) e o PCMSO - Programa de Controle Médico de Saúde Ocupacional (NR n ${ }^{0} 7$ ). O PPRA visa à preservação da saúde e da integridade física dos trabalhadores por meio da antecipação, reconhecimento, avaliação e consequente controle da ocorrência de riscos reais ou potenciais do ambiente de trabalho. Outra evolução ocorreu com a criação da CIPA - Comissão Interna de Prevenção de Acidentes (NR n ${ }^{0}$ 5), cuja finalidade é promover a melhoria das condições do ambiente de trabalho, pela ação dos próprios trabalhadores em cooperação com o empregador, voltada basicamente para um ambiente industrial.
Os esforços internacionais da OIT para a regulamentação de padrões de SST em atividade extrativista de grande escala nos anos 1990 repercutiram no Brasil. Em 1998, iniciou-se no país a discussão sobre a possibilidade de criação de um código de práticas florestais com base no Código de Práticas sobre Segurança e Saúde na Atividade Florestal definida pela OIT (Yashimita, 2005). Encontros e seminários foram promovidos para a discussão do tema e, para debater a criação de um possível código de segurança e saúde no trabalho florestal. A Fundacentro organizou, em 13 de agosto de 1999, um workshop sobre Código de Práticas em Segurança e Saúde no Trabalho Florestal que contou com a participação de representantes da OIT, do Departamento de Segurança e Saúde do Trabalhador (DSST), do Instituto de Pesquisa e Manejo Florestal (IMAFLORA), do Departamento de Ciências Florestais da ESALQ/USP e de representações de trabalhadores, como a Central Única de Trabalhadores (CUT), e de empregadores, como a Sociedade Brasileira de Silvicultura (SBS), além da participação de um especialista na implantação do código de práticas.

Tal código tinha como objetivo disciplinar as atividades e melhorar as condições de segurança e saúde dos trabalhadores na atividade florestal, já que nesse setor convivem diversos estágios de desenvolvimento e usos de tecnologias, como o da extração de madeira feito em florestas virgens, o corte de madeira com maquinário (motosserras) em florestas plantadas, sem organização e condições adequadas de trabalho, e o de empresas organizadas, que seguem as normas regulamentadoras urbanas e rurais, minimizando os riscos de acidentes e doenças ocupacionais. 0 código foi adotado em forma de lei, considerando-se a precariedade das condições de trabalho apresentadas no setor e a gravidade dos acidentes.

Com o objetivo de dar início às discussões da implantação do Código de Práticas em Segurança e Saúde no Trabalho Florestal, à Fundacentro coube a responsabilidade de traduzir o código de práticas da OIT para nortear um código nacional. Na época, havia esperanças de que o assunto entrasse na pauta de discussões da Comissão Tripartite Paritária Permanente (CTPP), criada no âmbito do Ministério 
do Trabalho em 2002 e, posteriormente, revogada e substituída pela Comissão Nacional Tripartite (CNT), em 2008, que tinha como objetivo incluir segmentos da sociedade civil no debate sobre SST na criação das NRs.

No ano de 200o, o Departamento de Segurança e Saúde do Trabalho (DSST) priorizou suas ações de fiscalização e normalização para os setores da agricultura e de florestas, com o início da revisão das Normas Regulamentadoras Rurais, contemplando, inclusive, o setor florestal. Essa ação ocorreu em decorrência do processo de discussão e construção da Convenção sobre Segurança e Saúde na Agricultura, iniciada pela OIT no mesmo ano e na qual a Fundacentro teve participação ativa.

A Fundacentro, por meio de parceria com a OIT, publica então o Código de Práticas em Segurança e Saúde no Trabalho Florestal em português. Quando a Norma Regulamentadora de Segurança e Saúde na Agricultura, Pecuária, Silvicultura, Exploração Florestal e Aquicultura - NR-31 - é publicada em 2005, acaba por contemplar a área florestal.

De fato, até hoje não existe um corpo de regras e normas, de caráter público ou privado, que regule os riscos de saúde e segurança envolvidos na atividade extrativista. Percebe-se, igualmente, que ainda não existe uma agenda de pesquisa consolidada que trate do extrativismo de pequena escala, realizado por trabalhadores informais, em atividades de subsistência, que envolva a coleta de PFNMs. Não deixa de ser paradoxal essa lacuna, porque os PFNMs estão sendo valorizados em agendas de pesquisa sobre meio ambiente e sustentabilidade pelo fato de apresentarem baixo impacto ambiental e contribuírem para a redução da pobreza em áreas rurais remotas (Andel; Mackinven; Bánki, 2003; Makishi; Veiga; Zacareli, 2015).

\section{As normas regulamentadoras de SST no Brasil}

A regulamentação existente no Brasil para SST está presente em leis, decretos, portarias, instruções normativas do Ministério do Trabalho e Emprego, Convenções da OIT ratificadas pelo Brasil, e nas normas regulamentadoras - as chamadas NRs. Estas estabelecem os requisitos técnicos e legais sobre os aspectos de Segurança e Saúde Ocupacional para ampla variedade de atividades. Por esta razão, este estudo as utilizou para confrontar as condições de trabalho dos coletores de sementes com a situação proposta pela norma.

A atividade extrativista é extremamente diversificada em razão da variedade de recursos naturais, suas características e a forma como estão disponíveis na natureza. Consequentemente, o trabalho nesta ocupação ocorre de diferentes formas, em várias configurações. Por exemplo, observa-se que os riscos à saúde e à segurança aos quais os coletores de andiroba na praia em Salvaterra estão expostos não são os mesmos para os coletores de murumuru na floresta amazônica em Bragança.

Várias NRs tangenciam a regulamentação de SST para a atividade extrativista e podem constituir fontes importantes de uma futura regulamentação específica. Na Tabela 1 estão relacionadas as NRs que tangenciam o extrativismo informal de pequena escala para PFNMs. Na coluna à direita estão os aspectos que podem ser objeto de consideração de uma futura NR para o extrativismo de PFNMs:

\section{Tabela I - Normas regulamentadoras e o extrativismo de PFNMs}

NORMA REGULAMENTADORA
NR-06: equipamentos de proteção de individual
NR-II: atividades de transporte de sacas
NR-17: levantamento, transporte e descarga de materiais
NR-2I: trabalho a céu aberto
NR-24: condições sanitárias e de conforto nos locais de
trabalho
NR-3I: agricultura, pecuária, silvicultura, exploração florestal
e aquicultura

ADAPTAÇÃO AO EXTRATIVISMO

Luvas, botas, protetor solar e chapéu

Limite de peso e percurso (tempo e distância)

Peso, percurso e as condições de entrega

Chapéu, protetor solar e acesso à água potável

Praias, margens de rios e igarapés, áreas de várzea indicam

limite temporal para a atividade de coleta

NR que mais se aproxima da atividade de coleta de PFNMs 
Porém, como estas normas estão definidas para os trabalhadores registrados cuja relação é estabelecida pela Consolidação das Leis do Trabalho (CLT), elas não abrangem o extrativismo cuja característica do trabalho é a informalidade em várias dimensões: não há jornada definida; a coleta é sazonal; não existe propriamente um local (praias, margens de rios e igarapés, áreas de várzea e floresta); a atividade pode ser exercida em ampla extensão territorial; e os coletores podem trabalhar individualmente ou em grupo. Não há ainda uma divisão de trabalho estabelecida, embora exista a predominância de gênero, e o envolvimento familiar (cônjuges e crianças). No entanto, no limite, todos os coletores podem executar a mesma função, a de coleta, transporte e/ou armazenamento.

\section{Resultados empiricos}

A atividade de coleta e armazenamento de sementes e frutos oleaginosos na Amazônia pode ser dividida, de forma geral, em seis etapas: deslocamento dos coletores, coleta, transporte das sementes, secagem, acondicionamento e armazenamento. A análise apresentada em tela volta-se para as três etapas iniciais envolvendo a atividade de coleta propriamente dita e o transporte de sementes. As etapas se diferem no que diz respeito ao ambiente onde se desenvolvem. A coleta em Salvaterra é feita nas praias próximas à cidade; já em Bragança, acontece em áreas de floresta, que podem ser de várzea ou secas. Nas praias, os coletores podem deparar com arraias (sob água parada no raso), objetos cortantes e/ou perfurantes (pedaços de vidro e restos de metal) e até mesmo material contaminado (pregos e parafusos enferrujados), dentre outros. Já na floresta, os coletores podem ser ameaçados pela presença de animais peçonhentos como cobras, escorpiões e aranhas, além de espinhos de algumas espécies vegetais.

Em relação aos perigos aos quais o trabalhador extrativista está sujeito, é possível traçar um paralelo entre a atividade de coleta em Bragança com atividades de extração de madeira e silvicultura, como descritos por Canto et al. (2007), enquanto a coleta de sementes em Salvaterra se assemelha à atividade das marisqueiras analisado por Pena, Freitas e Cardim (2011). É preciso notar que a dedicação dos trabalhadores de Bragança e Salvaterra às respectivas atividades de coleta não são exclusivas, ou seja, estes trabalhadores desenvolvem diferentes atividades, incluindo agricultura, pesca e coleta de outras espécies de sementes. Tal característica é refletida na caracterização do local de trabalho, predominantemente florestal em Bragança e majoritariamente praiana em Salvaterra (Figura 1). O caráter plural da atividade rural encontrada nestas localidades serve de justificativa para o exercício de buscar um denominador comum em termos de SST e análise conjunta aqui realizada. Muitos das conclusões apontadas, ao final da análise, aplicam-se a ambos os casos.

Com base nos depoimentos dos trabalhadores entrevistados, os riscos foram agrupados em quatro categorias conforme sua natureza, sendo elas decorrentes do ambiente, organização do trabalho, pessoas e materiais. As principais causas de acidentes e de problemas de saúde dos trabalhadores extrativistas estão listadas no Quadro 1.

\section{Figura I - Ambiente das atividades de coleta de PFNMs}

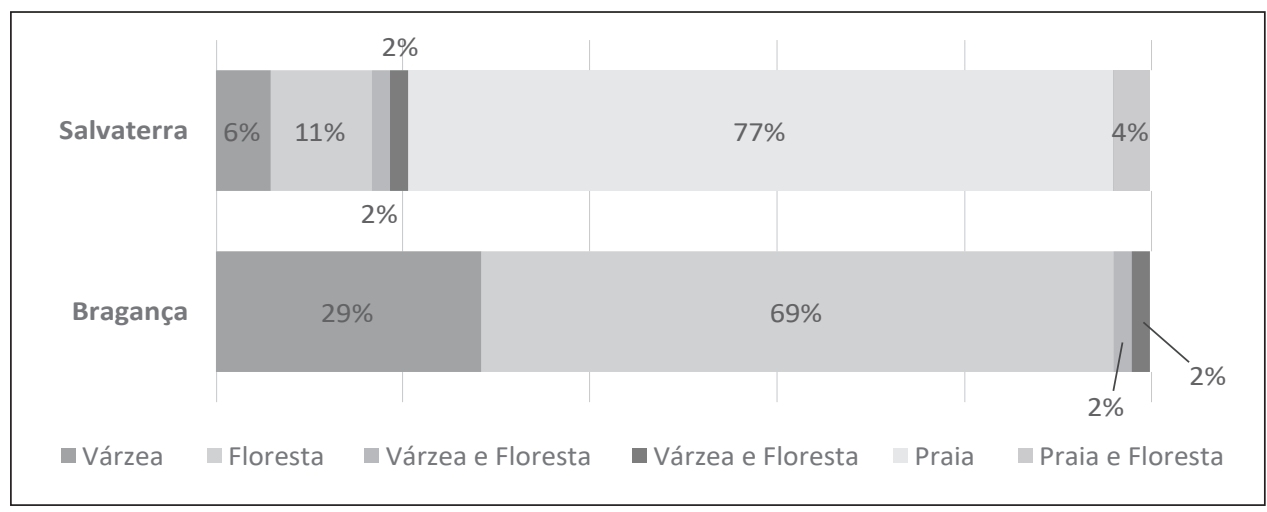


Quadro I - Natureza dos riscos no extrativismo dos PFNMs

\begin{tabular}{|c|c|c|}
\hline Tipo de risco & Fator de risco & Situação de trabalho \\
\hline \multirow{3}{*}{ Físico e biológico } & $\begin{array}{l}\text { Calor } \\
\text { Umidade e chuva } \\
\text { Radiação solar }\end{array}$ & $\begin{array}{l}\text { Trabalho e deslocamento ao ar livre em áreas costeiras e na mata com } \\
\text { exposição ao sol. }\end{array}$ \\
\hline & Objetos perfurantes e cortantes & $\begin{array}{l}\text { Risco de ferimento por espinhos, objetos cortantes e galhos na mata e } \\
\text { nas praias. }\end{array}$ \\
\hline & Animais & $\begin{array}{l}\text { Exposição a animais perigosos, risco de picadas e mordidas (aranha, } \\
\text { escorpião, cobra, abelhas etc.). }\end{array}$ \\
\hline Laboral & $\begin{array}{l}\text { Sazonalidade } \\
\text { Relações de trabalho } \\
\text { Falta de capacitação }\end{array}$ & $\begin{array}{l}\text { Trabalho de coleta pode ocorrer em locais distantes das residências e } \\
\text { do local de secagem e armazenamento das sementes. }\end{array}$ \\
\hline Pessoal & Costumes & O uso de EPI é pouco difundido entre a população. \\
\hline \multirow[t]{2}{*}{ Material } & Transporte & $\begin{array}{l}\text { Risco de afogamento e naufrágio por sobrecarga das canoas utilizadas } \\
\text { para deslocamento (Salvaterra); problemas ergonômicos podem ser } \\
\text { agravados durante o deslocamento (Salvaterra e Bragança). }\end{array}$ \\
\hline & Falta de acesso aos EPIs & Não existe mercado local de EPIs. \\
\hline
\end{tabular}

Praticamente todos os entrevistados apontaram o alto risco de picadas de cobra na região $(79 \%$ em Salvaterra e 80\% em Bragança), e ainda foram relatados casos em que alguns dos coletores foram vítimas de tal ameaça.

O uso de EPI é ainda pouco frequente junto ao trabalho extrativista. Na maioria das vezes são adquiridos pelos próprios trabalhadores. Dos entrevistados, $41 \%$ e $45 \%$, respectivamente em Bragança e Salvaterra, declaram não utilizar EPIs por falta de hábito ou costume.

0 crescimento da demanda pela indústria processadora de insumos naturais da biodiversidade na região amazônica tende a intensificar a atividade, aumentando a ocorrência de acidentes e lesões.

A relação de frequência de uso de equipamentos de segurança individual retratada junto às duas comunidades está representada pela Tabela 2.

Em ambos os casos se verifica que menos de $5 \%$ dos entrevistados utilizam frequentemente protetor solar. É possível que isso ocorra porque os efeitos da exposição ao sol são verificados em longo prazo e, por isso, considerados de menor relevância. A utilização de EPIs em Bragança, de acordo com a resposta dos entrevistados, é superior a Salvaterra: bota/calçado (62\%), luva (42\%), chapéu (39\%) e protetor solar (5\%). Em Salvaterra, a frequência das respostas diminui consideravelmente: bota/calçado (22\%), luva (5\%), chapéu (21\%) e protetor solar (2\%).

\section{Tabela 2 - Frequência no uso dos EPIs}

\begin{tabular}{lcc} 
& \multicolumn{2}{c}{ Local/ Frequência de } \\
UPI & \multicolumn{2}{c}{ utilização } \\
\cline { 2 - 3 } & Salvaterra & Bragança \\
Bota ou calçado & $25 \%$ & $67 \%$ \\
Luvas & $11 \%$ & $43 \%$ \\
Calça e blusa de manga longa & $25 \%$ & $39 \%$ \\
Chapéu & $6 \%$ & $33 \%$ \\
Protetor solar & $4 \%$ & $2 \%$ \\
Colete salva-vidas & $0 \%$ & $0 \%$ \\
Não usa qualquer tipo de EPI & $21 \%$ & $51 \%$ \\
\hline
\end{tabular}

Nos dois municípios foi observado que quase $50 \%$ dos entrevistados não utilizam os equipamentos de segurança por uma questão de hábito (45\% em Salvaterra e $41 \%$ em Bragança), uma demonstração evidente de falta de informação, por um lado, e uma dificuldade de implementação de uma possível norma de utilização de EPIs, por outro. De qualquer forma, a maior parte dos coletores não conseguiu internalizar em seu comportamento a importância do uso de EPIs. Um dos fatores que explica esta situação está ligado ao não costume de utilizar este tipo de equipamento, que, em alguns 
casos, é considerado um obstáculo à coleta, como é o exemplo em que o coletor precisa sentir com as mãos se as sementes e frutos estão em bom estado para a extração de óleo. A solução poderia ser encontrada na utilização de equipamentos que não prejudicassem a superfície de contato ao mesmo tempo em que proteja as mãos dos coletores.

A ergonomia da atividade de coleta de sementes e frutos oleaginosos foi analisada pela observação direta da atividade de coleta e pela ocorrência de lesões retratada pelos trabalhadores. Cerca de $60 \%$ dos entrevistados de Bragança relatam sentir dores nas costas, região lombar, sobretudo no período de safra. Em Salvaterra, 63\% fizeram a mesma queixa. Os trabalhadores de Bragança relataram ainda sentirem dores na região do quadril
$(12,5 \%)$ e pernas $(12,4 \%)$, enquanto em Salvaterra estas dores específicas são menos frequentes, 8,3\% e 5,3\%, respectivamente. Tais ocorrências podem ser atribuídas à postura durante a coleta, ao tempo de atividade e à distância entre locais de coleta e de armazenamento. Movimentos contínuos de se abaixar e se levantar forçam a musculatura da espinha dorsal, o que pode causar lesões de maior gravidade com o tempo.

Nas duas localidades, cerca de $6 \%$ dos entrevistados informaram sentir dores de cabeça ao menos uma vez no final da jornada de trabalho. Tal aspecto pode ser associado à baixa hidratação, exposição excessiva ao sol, calor e umidade. Fontes locais relatam que a temperatura frequentemente passa dos $35^{\circ} \mathrm{C}$ na floresta e dos $30^{\circ} \mathrm{C}$ na praia.

\section{Tabela 3 - Síntese das informações obtidas no trabalho de campo}

\begin{tabular}{lll} 
& BRAGANÇA & SALVATERRA \\
\hline Local onde realiza a coleta & $69 \%$ em florestas & $77 \%$ na praia \\
Tempo de deslocamento até o local da coleta & 12,5 minutos & 25 minutos \\
Motivo para não utilizar EPI & $41 \%$ por hábito & $45 \%$ por hábito \\
Considera que a atividade apresenta algum risco & $91 \%$ & $87 \%$ \\
Riscos aos quais estão expostos & $79 \%$ temem cobra & $78 \%$ temem cobra \\
Parte do corpo onde sentem dor & $60 \%$ sentem dores nas costas & $64 \%$ sentem dores nas costas \\
Periodo em que realizam coleta & $67 \%$ coletam durante a manhã & $60 \%$ coletam durante todo o dia \\
\hline
\end{tabular}

Apesar da distinção nos locais de trabalho em Salvaterra e Bragança, os riscos são praticamente os mesmos. Em relação à utilização de EPIs, foi encontrada uma população um pouco mais instruída em Bragança em comparação a Salvaterra. Bragança é uma cidade mais bem equipada no que se refere à oferta de escolas e foi um município importante do ponto de vista econômico no início do século XX. Como a coleta em Bragança acontece mais em floresta do que em praia, é normal que os coletores utilizem calçados para a atividade extrativista. Outro ponto importante é que os coletores em Salvaterra usam mais chapéu devido ao ambiente da praia ter uma maior exposição aos raios solares do que na floresta, em que a vegetação se torna uma proteção natural. Essas particularidades apresentam desafios para uma possível regulamentação específica ao extrativismo no que se refere à SST.

\section{Conclusão}

A demanda por insumos naturais da biodiversidade amazônica deve aumentar nos próximos anos por conta do número de empresas processadoras interessadas em desenvolver projetos de pesquisa comercial para óleos, essências e fragrâncias a partir de PFNMs. Essa mudança vem junto da preocupação com o uso sustentável dos recursos naturais, do incentivo à preservação das áreas de floresta, e da necessidade de inclusão social das famílias coletoras de PFNMs. Um resultado previsível dessa nova agenda de desenvolvimento para a Amazônia aponta 
para o aumento do risco de acidentes em razão dos problemas de SST que o extrativismo acarreta.

Os dados e os resultados discutidos anteriormente apontam diferenças entre as localidades, mas ao mesmo tempo indicam a necessidade de se criar mecanismos institucionais e de monitoramento das comunidades locais no que se refere ao uso dos EPIs. Como fora observado, os desafios são praticamente os mesmos em ambas as localidades e perpassam todos os momentos do processo de extrativismo das sementes - da coleta ao armazenamento. A postura no momento da coleta e o transporte das oleaginosas e as ameaças locais como animais peçonhentos e lixo depositado de forma inapropriada nas áreas de coleta são os principais riscos aos quais os coletores estão expostos.

Uma nova NR para o extrativismo, além de possuir o potencial para gradativamente resolver estes riscos, pode ser aplicada a qualquer bioma em qualquer comunidade rural do território brasileiro. Contudo, uma decisão tomada em Brasília terá problemas de adesão às regras (compliance), porque ela pode não levar em consideração "os saberes locais”, além de constituir um mínimo denominador comum de recomendações que deverá sofrer adaptações por conta do contexto local.

No caso de cooperativas e associações de produtores, os coletores tomam a decisão coletiva de internalizar as normas de SST, o que representa custo adicional a cada família. Nesse caso, a questão é evitar o carona, aquele que manifesta a intencionalidade de aderir às regras, ou seja, é membro da cooperativa ou da associação, mas, na realidade, não internaliza as normas na coleta, não arca com seus custos. Dessa forma, a questão desloca para o monitoramento. Em cooperativas e associações de pequena escala, o automonitoramento é a prática usual, ou seja, não há autoridade acima dos próprios cooperados que possam avaliar ou auditar suas práticas. Nesse caso, o problema é saber se há incentivos na organização da cadeia produtiva para que os cooperados monitorem suas próprias práticas de SST.

Neste contexto e devido à heterogeneidade de situações para o extrativismo, faz-se aqui algumas sugestões, quais sejam, os cuidados mínimos que servem à prevenção de acidentes. Para prevenir picadas de animais peçonhentos, o uso de botas de cano alto ou de perneiras de couro com botina por parte dos coletores evita até $80 \%$ dos acidentes, conforme a "Cartilha de Ofidismo" (Alves et al., 1988). Além disso, sugere-se o uso de um graveto ou pedaço de pau comprido para remexer em montes de lixo ou folhas e não ser preciso abaixar para manipular o lixo antes de coletar.

Com relação ao risco de ferimentos ocasionados por espinhos, o uso de luvas e/ou mangas de proteção reduz significativamente os perigos de lesões provocadas por materiais perfurantes, protegendo os membros superiores. Orienta-se ainda o uso de protetor solar nas áreas expostas ao sol e o uso de chapéu de palha de abas largas e cor clara para a proteção da cabeça, além do uso de camisa de mangas compridas.

Dentre as operações de manuseio de cargas (no caso do transporte dos sacos com a coleta), aquela do tipo "levantamento" é a que em geral mais solicita a coluna lombar. Para evitar lesões nessa região, sugere-se utilizar técnicas de levantamento manuais adequadas, em função das características antropométricas, biomecânicas e fisiológicas do operador e da frequência de levantamento. Para isso, deve-se observar algumas regras básicas: posicionar os pés corretamente; utilizar os músculos das pernas e não os das costas; manter o dorso plano; manter os braços juntos ao corpo; posicionar corretamente as mãos na carga; e utilizar o peso do corpo.

O uso de algum instrumento de transporte de carga, tal qual, um animal de carga ou um "carrinho de mão" para fazer o transporte das sementes do local de coleta até os polos de armazenamento, pode amenizar os problemas relacionados ao manuseio de carga. Pausas durante a coleta evitam fadiga demasiada por parte dos coletores. Essa pode vir a ocorrer em local protegido de chuva e sol. Deve-se ainda, garantir o acesso ao soro antiofídico, em locais próximos as áreas de coleta, e o acesso a serviços de assistência médica.

Uma questão ainda permanece: deve-se aguardar por uma nova NR exclusiva para o extrativismo, ou seja, o governo promove uma regulamentação pública top-down de caráter obrigatório, ou os próprios coletores, por meio de ação coletiva local, podem melhorar a adesão às regras, de maneira voluntária? 


\section{Referências}

ALENCAR FILHO, J. G. Ergonomia. Recife: Fesp/ UPE, 1993. (Apostila do Curso de Especialização em Engenharia de Segurança do Trabalho).

ALLEGRETTI, M. H. Reservas extrativistas: parâmetros para uma política de desenvolvimento sustentável na Amazônia: o destino da floresta. Rio de Janeiro: Relume Dumará, 1994.

ALVES, A. L.; GIMENEZ A. R. M.; VENTURA D. V. R. Cartilha de ofidismo (Cobral). Brasília, DF: Ministério da Saúde, 1988.

ANDEL, T. R. V.; MACKINVEN, A.; BÁNKI, O. S. Commercial non-timber forest products of Guiana Shield: an inventory of commercial NTFP extraction and possibilities for sustainable harvesting. Amsterdam: Netherlands Committee for the IUCN, 2003.

BOSTRAND, L. Introduction to ergonomics in forestry in developing countries. Roma: Food and Agriculture Organization of the United Nations, 1992.

CÂMARA, G. R.; ASSUNÇÃO, A. Á.; LIMA, F. P. A. Os limites da abordagem clássica dos acidentes de trabalho: o caso do setor extrativista vegetal em Minas Gerais. Revista Brasileira de Saúde Ocupacional, São Paulo, v. 32, n. 115, p. 41-51, 2007.

CANTO, J. L. et al. Avaliação das condições de segurança do trabalho na colheita e transporte florestal em propriedades rurais fomentadas no estado do Espírito Santo. Revista Árvore, Viçosa, v. 31, n. 3, p. 513-520, 2007.

CANTO, S. A. E. Processo extrativista do açaí: contribuição da ergonomia com base na análise postural durante a coleta dos frutos. Dissertação (Mestrado em Engenharia de Produção) Universidade Federal de Santa Catarina, Florianópolis, 2001.

CLÜSENER-GODT, M.; SACHS, I. Extractivism in the Brazilian Amazon: perspectives on regional development. Paris: Unesco, 1994.

COX, M. A basic guide for empirical environmental social science. Ecology and Society, Wolfville, v. 20, n. 1, p. 63, 2015.
DIEGUES, A. C. et al. (Org.). Os saberes tradicionais e a biodiversidade no Brasil. São Paulo: Nupaub-USP, 2000.

FAO - FOOD AND AGRICULTURE ORGANIZATION OF THE UNITED NATIONS. Non-wood forest products for rural income and sustainable forestry. FAO

Technical Report, n. 7. Roma: FAO, 1995.

FARIA, R. B. M. Povos indígenas na Amazônia e o mercado de produtos florestais não madeireiros: efeitos no uso de recursos naturais pelos Araweté. 2007. Dissertação (Mestrado em Ciência Ambiental) - Universidade de São Paulo, São Paulo, 2007.

FONSECA, E. D. et al. Conexões de saberes sobre o trabalho: construindo ferramentas para abordagens em SST. São Paulo: Fundacentro; Belo Horizonte: UFMG, 2015.

GOMES, V. L. B.; CARVALHO, R. S. C. Trabalho extrativista e condições de vida de trabalhadores: famílias da Ilha do Combú (Pará). Argumentum, Vitória, v. 4, n. 2, p. 208-224, 2012.

GRANDJEAN, E. Manual de ergonomia: adaptando o trabalho ao homem. Porto Alegre: Artes Médicas, 1998.

GUARIGUATA, M. R. et al. Compatibility of timber and non-timber forest product management in natural tropical forests: perspectives, challenges and opportunities. Forest Ecology and Management, Amsterdam, v. 259, n. 3, p. 237-245, 2010.

HALL, P.; BAWA, K. Methods to assess the impact of extraction of non-timber tropical forest products on plant populations. Economic Botany, Bronx, v. 47, n. 3, p. 234-247, 1993.

IBGE - INSTITUTO BRASILEIRO DE GEOGRAFIA E ESTATÍSTICA. Censo 2010. Rio de Janeiro, 2011. Disponível em: <https://goo.gl/HNFMS2>. Acesso em: 15 nov. 2015 .

IBGE - INSTITUTO BRASILEIRO DE GEOGRAFIA E ESTATÍSTICA. Produção da extração vegetal e da silvicultura. Rio de Janeiro, v. 24, 2009.

ILO - INTERNATIONAL LABOUR ORGANIZATION. Safety and health in forestry work. Genebra, 1998. 
MAKISHI, F.; VEIGA, J. P. C.; ZACARELI, M. A. Impactos socioambientais dos produtos florestais não-madeireiros: estudos de caso da Amazônia Brasileira. Revista Electrónica de Investigação e Desenvolvimento, Beira, v. 1, n. 4, 2015.

MAZZEU, F. J. C.; DEMARCO, D. J.; KALIL, L. Segurança e saúde no trabalho. São Paulo: Unitrabalho; Brasília, DF: Ministério da Educação; Secad, 2007. (Coleção Cadernos de EJA).

MENDES, R.; CAMPOS, A. C. C. Saúde e segurança no trabalho informal: desafios e oportunidades para a indústria brasileira. Revista Brasileira de Medicina do Trabalho, Belo Horizonte, v. 2, n. 3 , p. 209-223, 2004.

OIT - OFICINA INTERNACIONAL DEL TRABAJO. Guía de seguridad e higiene en los trabajos forestales. Genebra, 1968.

PENA, P. G. L.; FREITAS, M. C. S.; CARDIM, A. Trabalho artesanal, cadências infernais e lesões por esforços repetitivos: estudo de caso em uma comunidade de mariscadeiras na Ilha de Maré, Bahia. Ciência \& Saúde Coletiva, Rio de Janeiro, v. 16, n. 8, p. 3383-3392, 2011.

PETERS, C. M.; GENTRY, A. H.; MENDELSOHN, R. Valuation of a tropical forest in Peruvian Amazonia. Nature, Londres, v. 339, p. 655-657, 1989.

PINTO, A. et al. Boas práticas para manejo

florestal e agroindustrial: produtos florestais não madeireiros: açaí, andiroba, babaçu, castanha do Brasil, copaíba, e unha-de-gato. Belém: Imazon; Manaus: Sebrae/AM, 2010.

PLOWDEN, C. The ecology and harvest of Andiroba Seeds for oil production in the Brazilian Amazon. Conservation and Society, Bangalore, v. 2, n. 2, p. 251, 2004.

RÊGO, J. F. Amazônia: do extrativismo ao neoextrativismo. Ciência Hoje, Rio de Janeiro, v. 25, n. 147, p. 62-65, 1999.

RICHARDS, E. M. Commercialization of non-timber forest product in Amazonia. Kent: Natural Resources Institute, 1993. (Socio-economic Series 2).

RICHARDSON, R. J. Pesquisa social: métodos e técnicas. São Paulo: Atlas, 1985.
ROCHA J. B. A. et al. Carregadores de açaí: análise ergonômica do trabalho de carregadores de açaí do Mercado Ver-o-Peso em Belém do Pará. Estudos e Pesquisas em Psicologia, Rio de Janeiro, v. 12, n. 2, p. 431-445, 2012.

SEIXAS, F. Avaliação do esforço físico dispendido em operações florestais: um exemplo na operação de colheita de sementes. Instituto de Pesquisas e Estudos Florestais, Piracicaba, v. 7, n. 22, p. 1-16, 1991. (Série Técnica IPEF).

TICKTIN, T. The ecological implications of harvesting non-timber forest products. Journal of Applied Ecology, Londres, v. 41, n. 1, p. 11-21, 2004.

VALERIANO, S. Cartilha sobre o trabalho florestal. 1. ed. Brasília, DF: OIT, Serviço Florestal Brasileiro, 2009.

VIANA, V. M.; MELLO, R. A. Ecology and management of Brazil nut populations in extractive reserves in Xapuri, Acre, Brazil. In: INTERNATIONAL UNION OF FOREST RESEARCH ORGANIZATIONS WORLD CONGRESS, 20., 1995, Tampere. Poster Abstracts... Tampere: IUFRO, 1995, p. 37-38.

YASHIMITA, R. Y. Segurança e saúde no trabalho florestal: código de práticas da OIT. São Paulo: Fundacentro, 2005.

WCED - THE WORLD COMISSION ON ENVIRONMENT AND DEVELOPMENT. Our Common Future. Oxford: Oxford University Press, 1987.

\section{Contribuição dos autores}

Abreu, Silva e Trevisani desenvolveram o questionário específico sobre SST e aplicaram a famílias de coletores; Makishi e Zacareli também aplicaram os questionários, sistematizaram e analisaram os dados; Veiga coordenou a pesquisa de campo e participou da análise dos dados.

Recebido: 01/07/2016

Reapresentado: 27/04/2017

Aprovado: 14/08/2017 